\title{
Optimization of Urban Street Lighting Conditions Focusing On Energy Saving, Safety and Users' Needs
}

\author{
* Dr. CHRISTINA SKANDALI ', M.A. Y.S. LAMBIRI ${ }^{2}$ \\ 1 \& 2 School of Applied Arts, Hellenic Open University, Greece \\ E mail: skandali.christina@ac.eap.gr E mail: std085851@ac.eap.gr
}

\begin{tabular}{|l|}
\hline A R T I C L E I N F O: \\
\hline Article history: \\
Received 15 July 2018 \\
Accepted 23 September 2018 \\
Available online 13 October \\
2018 \\
\hline Keywords: \\
Optimization of urban \\
street lighting, LED, \\
Adaptive lighting, \\
Environmental effect, \\
Users' safety. \\
\\
This work is licensed under a \\
Creative Commons Attribution \\
- NonCommercial - NoDerivs 4.0. \\
"CC-BY-NC-ND" \\
\hline
\end{tabular}

\section{A B S T R A C T}

The outdoor lighting constitutes a significant part of the night activities of people in contemporary cities. Nevertheless, in many cases, this may result in the increasing and irrational use of it affecting the users of public areas, the environment and driving safety. The subject of this paper is to extend the discussion on the subject, to provide answers and to suggest methods for the improvement of the existing conditions in urban street lighting through the use of new technologies and smart lighting management systems, with the aim of achieving a smooth relationship between the user's needs, safety, sustainability, quality of life and energy saving.

JOURNAL OF CONTEMPORARY URBAN AFFAIRS (2018), 2(3), 112-121. https://doi.org/10.25034/ijcua.2018.4726

www.ijcua.com

Copyright (C) 2018 Journal Of Contemporary Urban Affairs. All rights reserved.

\section{Introduction}

Optimization is defined as "the action of making the best or most effective use of a situation or resource" (https://en.oxforddictionaries.com/definition/o ptimization). In the case of urban street lighting, optimization constitutes the correlation of design with the restrictions of the lighting Regulations while using the latest technologies and "smart" lighting management systems. The purpose is to achieve the maximum possible energy saving and reduction of $\mathrm{CO} 2$ and at the same time ensure better living conditions to the users of the city; both drivers and pedestrians. Therefore, apart from the benefits on environmental issues, the study focuses on its effects on driving safety and the reduction of car accidents, the increase of drivers' and pedestrians' feeling of security, and urban crime in general. The ultimate goal of the research is to get a wide knowledge on the effects of the optimization of urban street lighting in all aspects of urban living conditions in modern cities.

*Corresponding Author:

School of Applied Arts, Hellenic Open University, Greece

E-mail address: skandali.christina@ac.eap.gr 


\section{Methodology}

For the purpose of the study, the scientific material used focuses on primary sources, European and International literature, scientific articles and papers related to the subject and a wide analysis of various case studies using applications from all around the world, mainly Europe and America. A critical composition of the findings leads to conclusions as well as in methods of improvement of the existing street lighting conditions, on the basis of the users' safety, the energy saving possibilities, and also the creation of fair, in terms of lighting, urban areas in connection with the least possible environmental impact.

Primarily the problems of "bad lighting" in urban areas are defined, then optimization methods are suggested in order to upgrade urban environments and in the end the impacts of optimization in the categorized problems are analysed.

\section{Literature Review}

\subsection{The definition of "bad lighting" in urban areas.}

"Bad lighting" is when the final lighting outcome in the streets causes problems to the users or to the city itself. "Bad lighting" can be caused by inappropriate design, wrong maintenance of the system or no maintenance at all. The role of the European Lighting Expert in projects is crucial (http://europeanlightingexpert.org/en/), as this person has the knowledge to best design a lighting system by using the Lighting Regulations appropriately, while integrating all other relevant parameters that need to be taken into consideration in each specific case.

"Bad lighting" design can have a negative impact on the environment (i.e. excessive energy consumption and carbon emissions, exacerbation of the phenomenon of light pollution and the impact of lighting on flora and fauna in protected areas). Furthermore, "bad lighting" can have a serious effect on peoples' health (disruption of the human circadian system), peoples' safety (i.e. risk in driving safely, lack of orientation and visibility, weakness of the eyes to adapt to sudden changes in environmental illumination, lack of face recognition and sense of security for pedestrians). It has been proven that serious car accidents happen when lighting is not appropriate or there is no lighting at all, having as victims' pedestrians too. Another serious aspect that might be correlated with "bad lighting" is crime. Of course, not all the factors co-exist at the same time, but in each specific case some of them tend to cause problems in the smooth operation of urban areas.

While living in a period of unusual urbanization most people consider as very important to live safely in attractive and friendly environments in modern cities. The growth of the urban population offers great opportunities for economic and social development, while at the same time it presents enormous challenges.

\subsection{Optimization techniques in order to improve street lighting conditions.}

"Good lighting design" based on Lighting Standards and the use of new technologies and lighting management systems are the two main parameters that will rule the whole discussion in order to examine the impact they have in the urban environment. Additionally to the above, "good lighting design" serves functionality that meets the needs of each case, while using good quality fittings in the right position, the appropriate colour temperature and many other parameters that need to be taken into consideration in order to obtain the ideal solution.

\subsection{Designing according to the Lighting Standards.}

The necessity of the rational use of street lighting to the safety of users, drivers and pedestrians at night imposed to the European Committee for Standardization (CEN) the need for the institutionalization of the Lighting Standard EN 13201 in 2004. With the evolvement of technology, the installation of innovative lighting solutions and the integration of street lighting control and management systems, was considered necessary to revise the existing standard. Therefore EN 13201:2014 has been published by the CEN/TC 169 in December 2014 which is based on the Technical Report of CIE 115/2010. The revised EN consists of five parts.

The whole idea of the CEN/TR 13201-1 (2014, p.5) is "to specify the lighting classes and give guidelines on the selection of the most appropriate class for a given situation". It also introduces Adaptive Lighting and dimming techniques in order to further reduce energy consumption and improve environmental conditions under reduced traffic volume during certain periods of night or under varying weather conditions. While adaptive lighting is applicable, luminance or illuminance levels can fluctuate but the other qualitative features such as uniformity and the threshold increment (TI) for disability glare as defined in EN 13201-2 remain unchanged. 
EN13201-2 (2015, p.6) "defines performance requirements in order to cover the visual needs of road users and considers environmental aspects of road lighting". EN13201-3 (2015, p.6) "specifies conventions and mathematical procedures to be adopted in calculating the photometric performance of road lighting installations", while EN13201-4 (2015, p.7) "specifies measurement conditions and procedures for measuring the photometric quality parameters of road lighting installations". Additionally, the conditions that might lead to inaccuracies are identified and precautions are provided to minimize potential errors. Finally, EN13201:5 (2015) introduces the Energy Performance Indicators of the designed system using the calculated Power Density Indicator (PDI/DP) and the calculated Annual Energy Consumption Indicator (AECI/De), in order to compare the energy performance of different lighting solutions and choose the best one for each specific situation.

The Standard categorizes the streets into three classes (M class for motorized traffic, $C$ class for conflict areas and $\mathrm{P}$ class for pedestrian and low speed areas) while introducing additional categories and criteria; the SC class for pedestrian areas for improving facial recognition and increase the feeling of safety and the EV class for situations where vertical surfaces need to be seen. In some cases, it is also necessary to take measures to control disability glare and/or control obtrusive light (EN13201-2:2015).

\subsection{Designing with LED technologies and "Smart" Lighting Management Systems (Adaptive Lighting)}

At a time when energy adequacy is imperative, lighting has turned towards saving energy, discovering and developing modern, environmental friendly lighting technologies with a special type of light source, Solid State Lighting (SSL). Light emitting diodes (LED) is a promising technology and a new trend in the lighting industry.

LED lighting systems surpass other lamp types, especially for their high energy efficiency, operational lifespan (up to 100.000h), directionality of light output that reduces undesirable environmental impact and increased glare. They have the ability to adapt to the spectral content as they are available in a CCT range, ensure lighting requirements with half the power of HPS lamps and are working with suitable lighting systems in order to meet the actual lighting needs ("The Realized Results of LED Streetlights: Seizing the Opportunity", 2017). They are also considered environmental friendly without containing mercury, IR and UV radiation and show resistance to high temperatures. They can be produced in a variety of sizes, they have the ability to switch colors without using filters and provide a wide range of dimming settings. It is a technology that is constantly evolving and its cost and performance are areas of continuous improvement (Brodrick, J. 2017).

LED technologies, optics and control systems provide the necessary tools for achieving highquality public lighting installations. The luminaires can be equipped either a) with builtin luminous intensity control systems, b) with pre-set luminance adjustment scenarios or c) communicate with a central remote control system. The right amount of light related to traffic density, road and weather conditions, where and when it is needed, is the preferred practice compared to any other method that requires switching off the lights. The combination of increased safety and return on investment due to energy saving makes adaptive street lighting technology the best solution ("The Voice of the Lighting Industry in Europe", 2016).

\section{Urban Street Lighting Optimization}

In the following sections, the effects of the optimization of street lighting by using LED technology and "smart lighting" management systems are investigated and analyzed with regards to energy saving, light pollution, car accidents and crime.

\subsection{Optimization and Energy Saving}

The large proportion of electricity consumed globally where combined with installation and maintenance, is one of the major costs of each society. This fact makes the use of new technology along with "smart" management systems necessary, in order to achieve the best possible energy saving, to avoid light pollution and at the same time reduce $\mathrm{CO} 2$ emissions. 
According to a study from International Energy Agency (IEA), lighting contributes up to $20 \%$ of the worlds' electrical usage. If efficient lighting systems apply worldwide, it is estimated that the world's electricity bill can be reduced to one-tenth

(http://www.revolite.com/energysavingprogra m.html).

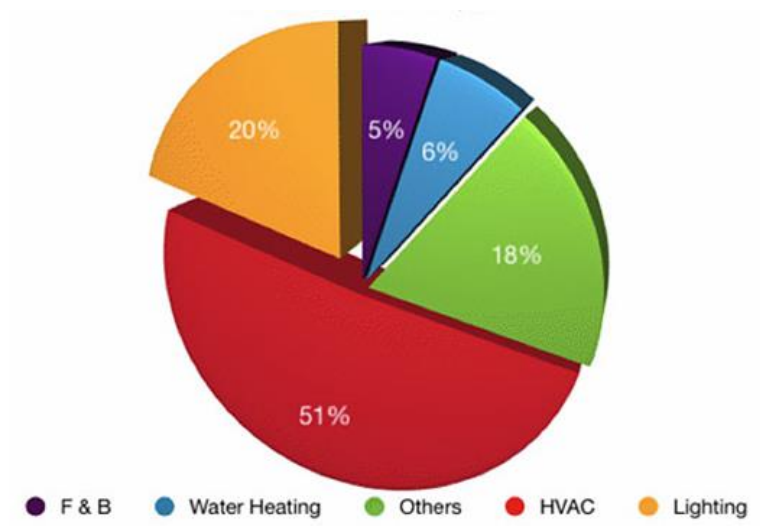

Figure 1. Global Electrical Consumption

(http://www.revolite.com/energysavingprogram.html)

At the same time while global climate changes, the rising cost of electricity and the need to reduce $\mathrm{CO} 2$ emissions are some of the key issues that the modern city is facing.

In 2010, the European Union has set as ambition for three energy targets to be achieved by 2020 ; a) the increase of energy efficiency by $20 \%$ from lighting, b) $20 \%$ reduction in $\mathrm{CO} 2$ and c) $20 \%$ of produced energy to come from renewable sources ("Lighting the Cities Accelerating the Deployment of Innovative Lighting in European Cities", 2013). Moving forward, the European Parliaments' new goals for 2030 are: a) a $40 \%$ reduction in Greenhouse Gas (GHG) emissions, b) at least $30 \%$ renewable energy sources and c) a $40 \%$ target for energy efficiency (Erbach, 2014).

Especially for street lighting, energy saving potential is expected to rise to $80 \%$ by 2020 ("World on the Edge by the Numbers - Shining a Light on Energy Efficiency", 2011 ), in order to save $€ 85$ billion annually for European consumers and at the same time reduce emissions by about 200 million tons of $\mathrm{CO} 2$, equivalent to 270 less power plants ("The Voice of the Lighting Industry in Europe", 2015). By 2027, LED and smart streetlights are projected to reach $89 \%$ and $29 \%$ of the total streetlight market, respectively ("Global LED and Smart Street Lighting: Market Forecast 2017-2027", 2017).

In most countries there is an obligation the design to follow the Lighting Standards with particular emphasis on energy saving. In 2008, a research towards this direction took place from the first major European Research Project, the E-Street project, for which representatives of the lighting industry, national energy organizations and some European municipalities have cooperated. The survey concluded that authorities across Europe could reduce street lighting energy bills by an average of $66 \%$ if they manage road lighting with flexibility, either by adjusting the light levels or by replacing old fittings with new LED systems ("Substantial savings from smarter street lighting", 2015).

\subsection{Optimization and Light Pollution}

For three billion years, the daily shift from light to darkness on the planet was governed by natural celestial sources, especially the moon, the airglow, the stars and the Milky Way (Kontorigas, 2007). The great revolution in artificial lighting that took place in the 19th century has led to the changing of the urban cities at night.

Light pollution describes the phenomenon of excessive outdoor lighting emitted to the sky, either directly or indirectly through reflections. The intense glare of street lighting, the over lighting of shopping windows, the advertising billboards and the increase of urban lighting for safety reasons, has led to the increase of the light glow of the sky and represents a profound change in the fundamental human experience. Even small increases in the sky brightness can deprive people from the opportunity to see the night sky.

Studies show that over $80 \%$ of the world and more than $99 \%$ of the US and European populations live under a light-polluted sky. Milky Way is not visible to more than a third of humanity, including $60 \%$ of Europeans and nearly $80 \%$ of North Americans Falchi et al, (2016)

According to the International Dark-Sky Association (IDA), light pollution is a multidimensional problem of our days with serious environmental consequences on humans, flora and fauna, but also of economic importance. Scientific evidence show that artificial light at night has negative and sometimes fatal effects on many living beings (amphibians, birds, mammals, insects and plants), causing their disorientation or problems in reproduction. Light pollution also affects the environment from the uncontrollable electricity consumption that leads to the depletion of energy resources and the direct increase of the carbon dioxide emissions (http://www.darksky.org/light-pollution/). 
Additionally, the phenomenon of light pollution does not leave astronomy unaffected (Walker, 1973).

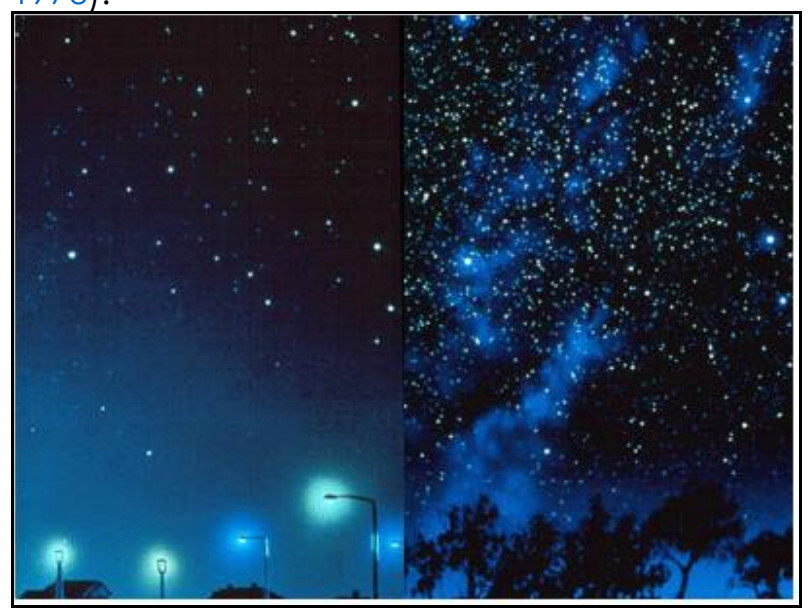

Figure 2. Before and during the 2003 Northeast blackout, a massive power outage that affected 55 million people. Photo by of Todd Carlson (http://www.darksky.org/lightpollution/).

The exposure to high light levels during the night has also a negative effect to humans on the transition to the normal stages of sleep as it contributes to the complete decomposition of circadian rhythm. Studies show that the circadian rhythm cycle controls $10-15 \%$ of our genes, therefore by interfering to that many health problems can be caused (Chepesiuk, 2009).

Lastly, light pollution can cause driving safety issues. Extremely high light levels in the streets can lead to the decrease of object visibility due to the reflection generated by bright light sources, with a direct impact on the driver's inability to locate pedestrians and adjacent obstacles, especially when the surrounding area is dark. Due to the above, serious car accidents may occur (Kraus, 2016).

Unlike many other forms of pollution, light pollution is reversible, therefore it should be addressed effectively. The basis for truly effective protection is (Walker, 1973), (Chepesiuk, 2009), ("Guidance Notes for the reduction of light pollution", 2000):

The applicable street lighting design based on lighting classes as defined by the Standards

- The installation of high quality lighting fixtures that reduce energy consumption by $60-70 \%$ can save billions of money and reduce $\mathrm{CO} 2$ emissions

- The use of fully shielded and full cut-off luminaires in order to reduce direct light emissions on the horizon while at the same time minimize the light reflected from the illuminated surfaces. In order to eliminate glare, the beam angle of the luminaires should be kept below $70^{\circ}$, as well as the position of luminaires in high poles to allow for lower beam angles. In areas with low level of ambient light, special care must be taken into consideration when installing and orientating the luminaires in order to minimize disturbing reflections.

- The use of warm white LED lamps ( $\leq 3000 \mathrm{~K}$ ) in order to avoid blue light that creates intense brightness in the sky and makes viewing more difficult at night.

Turn off lighting when used for decorative purposes or when it is not required for safety reasons.

- The installation of lighting management systems, presence/motion sensors and timers that help reduce average light levels and save even more energy.

\subsection{Optimization and Crime}

The sudden rise in crime that has been observed in recent decades in many countries worldwide has led to systematic measures in order to prevent it. The optimization of urban street lighting is intended for many purposes, one of which is the prevention of crime, towards people and properties in public areas. The correlation between urban light levels and the reduction of crime is the focus of long-term research.

A credible survey through experiments that has followed high-quality methodologies, was developed by UK Police College researchers to sum up the "best available" assessments of effective street lighting in relation to the reduction of crime levels. The study has shown that improved street lighting has a positive effect on reducing crime, such as burglaries and theft. However, it did not have any positive effect on violent crimes. Taking into account all the data of the survey, a relative $21 \%$ reduction of crime was found in the areas where light optimization was performed compared to similar areas where there were no corresponding interventions in lighting conditions ("The effects of improved street lighting on crime: What Works Briefing", 2008).

Regarding the correlation between street light levels and the reduction of crime, two main theories were developed. Firstly, improved lighting in urban areas contribute to the increase of surveillance, while the guarding by police is much easily achieved. Adequate lighting increases the risk of identifying and arresting the offenders. At the same time, people tend to use more the public spaces, 
increasing the number of potential witnesses in any violation that might take place. Secondly, the installation of efficient and effective lighting signifies and upgrades the marginalized areas, having as a result the minimization of criminal behaviors (Farrington and Welsh, 2008). However, as every area is unique, studies should clearly describe the nature and intensity of lighting improvements, the general neighborhood conditions, and other crime prevention actions in order to have reliable results (Clarke, 2008).

Most studies that analyze the relationship between the optimization of road lighting conditions and crime are mainly conducted by criminologists and not by lighting experts. Consequently, very few studies take into consideration street lighting designed according to the current Standards. In these cases available information usually refer either to the upgrading of lighting or increased light levels, better uniformity and colour rendering. In conclusion, by improving street lighting in an area, an upgrade of local community is achieved and at the same time a sense of security is provided. In other words, improved lighting is not a natural obstacle to crime, but contributes to the reduction of delinquent behaviors and can work as a catalyst for social action and cohesion but also as a mechanism that will contribute to further environmental improvements (Farrington and Welsh, 2008).

\subsection{Optimization and Car Accidents}

Through the research that has been carried out to date it is obvious that driving outside the daily hours is more dangerous. Only one fourth of all car drivers move between 07:00pm and 08:00am, and during this period of time $40 \%$ of fatal accidents and serious injuries happen ("Road Safety factsheet: Street Lighting and Road Safety", 2017).

Also, age range and the capabilities of nighttime drivers are different from those at daytime. For example, elderly people with visual impairment often avoid driving at night, while there may be more road users who have consumed alcohol or drugs or are simply very tired at night. In addition, average speed tends to be higher at night, partly because there is less traffic. Furthermore, there is likely to be a strong interaction between road lighting and the prevailing headlight technology of vehicles, causing accidents. The brightness of the headlamps has increased by about eight times over the past 60 years and at the same time street lighting has increased dramatically during the same period (Gaston et al, 2014).
According to European Commission statistics published on road safety in 2016, 25.500 people lost their lives in the EU streets and 135.000 people were seriously injured, $37 \%$ of which on average occurred in urban areas ("Road Safety factsheet: Street Lighting and Road Safety", 2017). Additionally in Switzerland, the number of fatalities with pedestrians as victims at night is $60-70 \%$ higher (Ghazwam, 2014).

The US Pedestrian Traffic Accident Report investigated data from 2006 to 2015 and found that during this ten year period pedestrian deaths as a percentage of total motor vehicle crash deaths increased from $11 \%$ to $15 \%$ in 2014 and 2015. About half of the pedestrian fatalities in 2015 occurred between 06:00pm and midnight, with $74 \%$ occurring after dark (Retting \& Scwartz, 2016). Similarly, the same conclusion came from a survey conducted by the University of Manchester's Institute of Science and Technology where it was found that low light is an important factor contributing to night time mortality. In particular, on motorways that are already lit, $2.6 \%$ of accidents are fatal compared to $4,3 \%$ of accidents where there is no illumination ("Road Safety factsheet: Street Lighting and Road Safety", 2017).

The effect of lighting on road accidents also depends on several factors, such as the street type, the speed limit, the traffic volume, the junction density and the traffic composition, always depending on the requirements of each lighting class. Additionally, visual performance while driving is a complicated issue as it is associated with a variety of elements such as uniformity, object visibility, visual targets, lighting of surroundings, weather conditions etc. (Ghazwan, 2014).

In a pilot study that took place in New Zealand's urban areas to assess the relationship between light levels and car accidents, it has been proved that the increase in traffic accidents is a matter of visibility and is associated with a reduction in the contrast between an object and its surrounding. The achieved average luminance or average illumination was important in all cases. The Threshold Increment (disability glare) was also an important factor in all experiments performed. The lower value of the $\mathrm{Tl}$ in conjunction with the achieved light levels is the second basic parameter for reducing accidents, while energy efficiency and uniformity levels were not statistically significant in any of the tested models. (Jackett and Frith, 2012).

Empirical evidence and a comparison of road traffic accidents revealed that the optimization 
of road lighting can actually prevent car accidents, as satisfactory light levels provide users with the ability to react faster and more accurately on the road surface. It also provides time to identify potential risks and the ability to react in a timely manner to prevent serious injuries. Particularly (Gastons et al, 2014), (Crabb and Crinson, 2017):

Road lighting on an urban road network can achieve an average reduction in accident rates of around $30 \%$ as an average percentage worldwide

- The benefits are directly connected with the parameters that determine the lighting class of the street

- Road lighting seems to have an impact on reducing the severity of accidents, and in particular on pedestrian-related accidents and not the car occupants

- The impact of road lighting is intensively reduced in conflict zones

- There may be hedging effects, in which lighting can lead to increased speeds and reduced concentration, but these effects are likely to be small

The installation of lighting posts is an additional risk that is often involved in a significant number of injured accidents, but it cannot be a reason for not installing lighting in the area.

\section{Analysis of worldwide case studies}

In our days, cities tend to consume $40 \%$ of their annual budget on electricity, while most road installations are outdated and extremely inadequate. There are about 300 million luminaires worldwide, most of them in urban areas and only $10 \%$ have been changed to LED. At the same time, the need for driving and pedestrians' safety is growing rapidly (Marinoa et al, 2016). Therefore, it is of great emergency to upgrade old installations with new technologies by using smart management systems.

For the purpose of this research, implemented cases have been studied such as Birmingham (UK), Mechelen (Belgium), Lyon (France), Tilburg and Eindhoven (Netherlands), Albertslund and Copenhagen (Denmark), Glasgow (Scotland), Gothenburg (Sweden), Helsinki (Finland), Norway, Canada, USA and others, in order to investigate the connection between theory and the real effect of lighting interventions in the urban environment and on users. The worldwide representative examples had as common the use of LEDs and dynamic lighting systems designed to be a key tool to make cities more "smart". Each case had its own targets to achieve according to its needs and used new technology for different reasons. In the analysed case studies, more than 100.000 luminaires were replaced in European cities and over 170.000 in America. The improvement of the lighting systems results in the following, without mentioning separately the benefits of each case.

a) Instant Cost Savings

The renewing of the street lighting systems with LED fittings and automations, correspond to direct cost savings from energy but also from system conservation.

All the cases achieved $30-60 \%$ energy saving while most of them between 50 and $60 \%$. When adaptive lighting is also used, further reduction to energy consumption is achieved, as in some cases luminaires are dimmed down to the least necessary levels.

Additionally, the new LED systems have extended lifetime (60.000-100.000 hours) compared to conventional lighting and extremely low failure rates, therefore it is expected immediate cost savings from reduced maintenance requirements. However, this will give accurate results after some years of operation.

The Light Savers Technical Advisory Committee (2017) evaluated 12 LED lighting fixtures in 7 cities worldwide. The scope of coverage included 29 different LED lights and adaptive lighting technologies used in parking areas, pedestrian paths, urban roads and high speed lanes. The results have shown that more than $70 \%$ of the new technologies have achieved at least $50 \%$ energy savings. In addition, the failure rate for all luminaires tested was $1.8 \%$ for an operating time between 4.000 and 6.000 hours, significantly lower than the typical HID failure rate of $10 \%$. In cases where LEDs were combined with adaptive lighting systems, they showed, at least, an extra savings of $20 \%$. Also, the majority of pedestrians and drivers agreed that visibility improved significantly ("The Realized Results of LED Streetlights: Seizing the Opportunity", 2017).

b) Environmental Benefits

The expected reductions in $\mathrm{CO} 2$ emissions can be calculated on the basis of the resulting energy reductions and the volume of carbon emitted from the electricity produced and varies between installations. Furthermore, when warm white colour temperature is used ( $\leq 3000 K)$ LED lighting systems emit more "friendly" light and cause less problems to the nature equilibrium. Additionally, due to the directionality of LEDs, there is less light pollution on roads and the problems of unnecessary 
diffusion and undesirable glare are reduced ("Road, paths and squares", 2014).

C) Reactions of the Road Users

Using LED lights usually increases light levels and achieves better lighting quality that improves visibility and thus drivers and public safety ("Road, paths and squares", 2014). In some cases there has also been observed a reduction in crime rates between 07:00pm and 07:00am; in crimes such as vehicle theft, burglary, robbery and vandalism. Additionally, the positive contribution of light bulbs with a recommended color temperature of $3000 \mathrm{~K}$ indicates that lighting can improve safety and driving safety, as well as contributing positively to the health of road users.

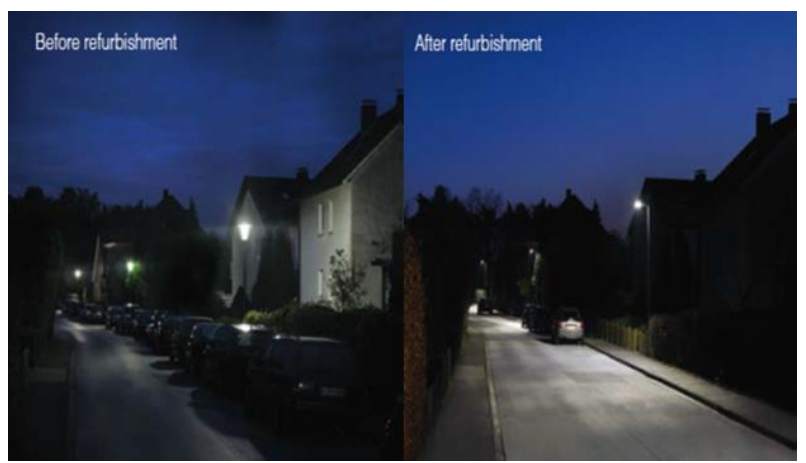

Figure 3. Before and after the refurbishment in a street in Bielefeld, Germany ("Road, paths and squares", 2014).

Apart from the key benefits mentioned above, each case had additional benefits due to the objectives that have been targeted in each individual case.

In the case of Lyon (France) for example, by using proximity sensors on the pedestrian bridge of Passerelle St. Vincent, the light levels were reduced to $10 \%$ when there was no pedestrian in the area. Additionally, the main street light levels were reduced by $60 \%$ overnight and they achieved a reduction in power consumption of more than $65 \%$ ("Lighting the Cities - Accelerating the Deployment of Innovative Lighting in European Cities", 2013). In the case of Eindhoven (Netherlands), street lights were programmed to blink red to alert residents to floods or storms. In the same way, they indicate an emergency evacuation route for traffic in case of a flood of the road or natural disasters ("Intelligent Road and Street Lighting in Europe", 2008). In the city of Patras (Greece), intelligent parking and smart lighting systems with specific sensors were installed in selected points so that drivers are immediately informed of the availability of a parking space (http://www.ypodomes.com). In
Norway, when snow covers the streets, the need for lighting is lower so the light levels are reduced ("Intelligent Road and Street Lighting in Europe", 2008).

The analysis of the implemented cases confirm the contribution of LED lighting systems into the creation of viable "smart cities", with optimal conditions for street users, the environment and the least possible energy consumption.

It is very important before an installation to have a pilot study, in which people also participate in order to analyze the real needs of each case. As it is shown above impacts on visibility, energy savings, capital costs, safety and environmental protection cannot be optimized with a single solution for all systems. New management lighting systems make it possible to adapt lighting to different needs at a time and place.

\section{Discussion}

Light contributes to the creation of the nighttime appearance of the city, which is depicted in a variety of ways according to its social, political, economic, cultural and geographical context and the current way of living. The purpose of this research was to find out the benefits of the optimization of street lighting conditions to the needs and reactions of users, to driving safety and the environmental effect. Key benefits of efficient urban lighting are demonstrated and information on International Standards and Regulations are provided in order to define a common framework for the development of street lighting with the ultimate goal of improving human life.

Improved lighting provides a sense of security and reduces offending behaviors, without being proved to be a physical obstacle to crime. An urban space that provides the feeling of safety can act as a catalyst for social action and cohesion but also as a mechanism that will contribute to further social upgrading and environmental improvement.

Similarly, empirical evidence has shown that properly designed areas in an urban road network can achieve a reduction in accident rates of about $30 \%$ worldwide. The benefit is directly dependent on variables related to the achieved light levels and the respective needs of the users. At the same time, the use of energy efficient light sources along with "smart lighting" management systems provide the possibility of creating a dynamic urban lighting that respond to the needs of each specific case and time, enhances energy saving and the reduction of $\mathrm{CO} 2$ emissions. 
Furthermore, the need for immediate action for the minimizing of light pollution is imperative. With careful selection, installation and targeting of modern light fixtures, the negative effects of the phenomenon can be avoided.

\section{Conclusion}

\subsection{Outcomes from optimizing urban lighting} conditions

In response to the quarries that have been stated at the beginning of the study, it has become obvious that flexible LED lighting solutions combined with a holistic approach of "good lighting design" according to the Lighting Standards provide to the urban road network excellent flexibility to the final outcome. This ability leads to a shift from "quantity" to "quality" that offers people and society a great deal of benefits. By summarizing, the benefits from the optimization of the street lighting urban network are listed below and are divided in three sections:
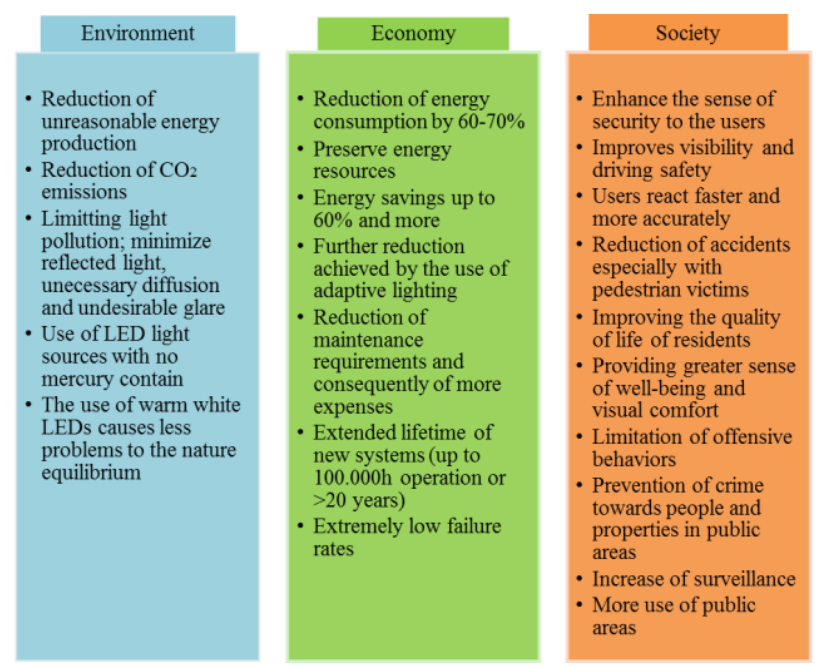

Figure 4. Street lighting optimization expected results (Developed by the Authors)

With this background and an interdependent relationship between lighting needs and aesthetics, the night-time appearance of the modern urban road network can become a new experience where visual comfort, safety and the opportunity to explore the urban environment can prevail.

\section{Acknowledgement}

This research did not receive any specific grant from funding agencies in the public, commercial, or not-for-profit sectors.

\section{References}

Brodrick, J. (2017). A New Resource on the Effects of LED Street Lighting U.S Department of Energy. Retrieved February 28, 2017 from https://energy.gov/

Chepesiuk, R. (2009, January). Missing the Dark Health Effects of Light Pollution. Environ Health Perspect. 117(1): A20-A27. https://doi.org/10.1289/ehp.117-a20

Clarke, R.V. (2008, December). Improving Street Lighting to Reduce Crime in Residential Areas. Problem-Oriented Guides for Police Response Guides Series No. 8. https://www.hsdl.org/?abstract\&did=682390

CN/TR 13201-1 (2014) Roadlighting - Part 1: Selection of lighting classes. European Committee For Standardization CEN. http://www.arpa.fvg.it/export/sites/default/ist ituzionale/servizi/inquinamento_luminoso/alle gati/cen_tr_13201-1_2004.pdf

Crabb, G.I., Crinson, L. (2017). The Impact of Street Lighting on Night Time Road Casualties. Retrieved from http://saferroadsconference.com/

EN 13201-2 (2015). Road lighting - Part 2: Performance requirements, European Committee For Standardization CEN. https://infostore.saiglobal.com/preview/9870 2708293.pdf?.skU=862133_SAIG_NSAI_NSAI_20 50991

EN 13201-3 (2015). Road lighting - Part 3: Calculation of performance. European Committee For Standardization CEN. https://infostore.saiglobal.com/preview/is/en 2015/i.s.en13201-3-2015.pdf? sku=1843912

EN 13201-4 (2015). Road lighting - Part 4: Methods of measuring lighting performance. European Committee For Standardization CEN

https://standards.globalspec.com/std/998200 8/cen-en-13201-4

EN 13201-5 (2015). Road lighting - Part 5: Energy performance indicators. European Committee For Standardization CEN. https://infostore.saiglobal.com/preview/is/en 12015/i.s.en13201-5-2015.pdf? sku=1843914

Erbach, G. (2014, March 24). EU climate and energy policies post - 2020 Energy security, competitiveness and decarbonisation. Retrieved from http://www.eprs.ep.parl.union.eu/

Falchi F., Cinzanol P., Duriscoe D., Kyba C.C.M., Elvidge C.D., Baugh K., Boris A. Portnov B.A., Rybnikova N.A. and Furgonil R. (2016, June 10). The new world atlas of artificial night sky brightness. Science Advances. Vol 2, no. 6. https://doi.org/10.1126/sciadv.1600377

Farrington, D. C. and Welsh B. P. (2008, September 24). Effects of improved street lighting on crime. Campbell Systematic 
Reviews.

2008:13,

https://doi.org/10.4073/csr.2008.13

Gaston, K., Gaston, S., Bennie, J., Hopkins, J. (2014). Benefits and costs of artificial nighttime lighting of the environment. Environmental Reviews, 2015. 23(1): 14-23, http://dx.doi.org/10.1139/er-2014-0041

Ghazwan, Al-Haji. (2014). The Impact of $\mathrm{New}$ Street Lighting Technologies on Traffic Safety. Journal of Traffic and Logistics Engineering. Vol. 2, No. 3. pp. 202-205. https://doi.org/10.12720/itle.2.3.202-205

Global LED and Smart Street Lighting: Market Forecast (2017-2027). (2017, November). Volume IV. Retrieved from http://www.northeast-group.com

Guidance Notes for the reduction of light pollution (2000). The Institution of Lighting Engineers (Revised 05/03). https://www.gov.je/SiteCollectionDocuments /Planning\%20and\%20building/SPG\%20Lightpo llution\%202002.pdf

Intelligent Road and Street Lighting in Europe (2008). Retrieved from https://ec.europa.eu/energy/intelligent/proje cts

Jackett, M., Frith, W., (2012, July). How does the level of road lighting affect crashes in $\mathrm{New}$ Zealand -A pilot study. Retrieved from http://www.nzta.govt.nz/

19 Kontorigas, T. (2007). Light pollution and quality of outdoor lighting. Retrieved June 9, 2017, from http://www.greekarchitects.gr/

Kraus, L. J. (2016). Human and Environmental Effects of Light Emitting Diode (LED) Community Lighting. Report of the council on science and public health. CSAPH Report 2A-16. https://www.darksky.org/ama-reportaffirms-human-health-impacts-from-leds/

Lighting the Cities - Accelerating the Deployment of Innovative Lighting in European Cities (2013, June). Retrieved from https://ec.europa.eu/digital-singlemarket/en/news/new-commission-reportlighting-cities-accelerating-deploymentinnovative-lighting-european

Marinoa, F., Leccesea, F., Pizzutib, S. (2016). Adaptive street lighting predictive control. 8th International Conference on Sustainability in Energy and Buildings, SEB-16, 11-13 September 2016, Turin, ITALY. https://doi.org/10.1016/j.egypro.2017.03.241

Retting, R. and Scwartz, S. (2016). Pedestrian Traffic Fatalities by State. Retrieved March 27, 2018 from https://www.ghsa.org/sites/

Road, paths and squares (2014). Retrieved from http://en.licht.de/
Road Safety factsheet: Street Lighting and Road Safety. (2017, March). Retrieved from https://www.rospa.com/

Substantial savings from smarter street lighting (2015, January \& February). Retrieved from http://www.itsinternational.com/sections/gen eral/features/substantial-savings-fromsmarter-street-lighting/

The effects of improved street lighting on crime: What Works Briefing. (2008). Retrieved from http://library.college.police.uk/docs/whatworks/What-works-briefing-improved-streetlighting-2013.pdf

The Realized Results of LED Streetlights: Seizing the Opportunity (2017, January 31). Retrieved from https://static 1.squarespace.com/

The Voice of the Lighting Industry in Europe (2016). Retrieved from https://www.lightingeurope.org/

Walker, M. F. (1973, October). Light Pollution in California and Arizona. Publications of the Astronomical Society of the Pacific. Vol. 85. No. $507 . \quad$ p.508. http://adsabs.harvard.edu/full/1973PASP...85. $.508 \mathrm{~W}$

World on the Edge by the Numbers - Shining a Light on Energy Efficiency (2011, July 12). Retrieved from www.earthpolicy.org/data_highlights/2011/highlights 15 